This is the peer reviewed version of the following article: Ireland, A. V. (2017), Simulated human patients and patient-centredness: The uncanny hybridity of nursing education, technology, and learning to care. Nurs Philos, 18:e12157, which has been published in final form at https://doi.org/10.1111/nup.12157. This article may be used for non-commercial purposes in accordance With Wiley Terms and Conditions for self-archiving. 


\title{
Simulated human patients and patient-centredness: the uncanny hybridity of nursing education, technology, and learning to care
}

\begin{abstract}
Positioned within a hybrid of the human and technology, professional nursing practice has always occupied a space that is more-than-human. In nursing education, technology is central in providing tools with which practice knowledge is mobilised so that students can safely engage with simulated human patients without causing harm to real people. However, while there is an increased emphasis on deploying these simulated humans as emissaries from person-centred care to demonstrate what it is like to care for real humans, the nature of what is really going on in simulation - what is real and what is simulated - is very rarely discussed and poorly understood.
\end{abstract}

This paper explores how elements of postcolonial critical thought can aid in understanding the challenges of educating nurses to provide person-centred care within a healthcare culture that is increasingly reliant on technology. Because nursing education is itself a hybrid of real and simulated practice, it provides an appropriate case study to explore the philosophical question of technology in healthcare discourse, particularly as it relates to the relationship between the human patient and its uncanny simulated double. Drawing on postcolonial elements such as the uncanny, diaspora, hybridity and créolité, the hybrid conditions of nursing education are examined in order to open up new possibilities of thinking about how learning to care is entangled with this technological space to assist in shaping professional knowledge of person-centred care. Considering these issues through a postcolonial lens opens up questions about the nature of the difficulty in using simulated human technologies in clinical education, particularly with the paradoxical aim of providing person-centred care within a climate that increasingly characterised as posthuman.

Keywords: high-fidelity simulated human patients, nursing education, postcolonial, uncanny, person-centred care 


\section{Introduction}

Nursing practice, from its mythical beginnings with Nightingale and her lamp, has always been bound up within a hybrid space of the human and technology (Forss 2015). As nursing knowledge progresses, the boundaries between the human and technology within healthcare contexts have increasingly blurred, creating the automaton fusion that positions the human patient as cyborg. As Braidotti (2013) argues, it is the effects of scientific and technological advances that have displaced the boundaries between the categories of the binary opposition of nature-culture and created an overlapping at the point at which humans and technology intersect. Thus, it is no longer possible to understand the human condition without also taking into account the shift that has occurred within the technological concepts, methods and practices that have transformed our knowledge of caring for human beings. Consequently, the ways in which this knowledge is mobilised in nursing education must also rely on the fusion of both human and non-human materialities that are persistently permeated with the technological imaginings of 'real' practice. Braidotti (2013) argues that, until very recently, the Eurocentric paradigm placed the human at the centre of scientific knowledge, an ideology that was opposed by the poststructuralist generation, providing a foundation on which we might understand the human condition as posthuman. Posthumanism itself is a contradictory and contentious subject, but Braidotti's positioning of the posthuman subject goes beyond merely considering how the advancement of technology has dissolved the margins of human and materials to create cyborgs by presenting posthumanism as "an opportunity for humanity to reinvent itself affirmatively, through creativity and empowering ethical relations" (2013, p. 195) rather than as something negative to be resisted and contested. For Braidotti, the posthuman challenges the social constructivist approach to the "given (nature) and the constructed (culture)" (2013, p. 2) to provide a way of thinking about our shared human identity to provide a more adequate representation of the human in the bio-genetic age. In 
this way, the cyborg human subject is not seen as a single entity, placed in the centre, but instead can be understood as being a hybrid of human and technology, occupying a space where human and non-human overlap. As such, the cyborg human condition, in having a fluid and emergent ontology, is capable of occupying multiple identities and heterogeneous ways of perceiving the world. Similarly, accelerating advancements in the employment of biotechnologies and information systems in medical care positions the human body as cyborg: a hybrid of biology and technology where caring for these bodies is situated in "a space for the dematerialization into a prosthetic body, a space for postbiological and posthuman aesthetic, a space for cloning, replication, robotics, human action simulation, or memory uploading" (Monteiro 2016, p. 23). As humans navigate this hybrid terrain, it is helpful to acknowledge the challenges that healthcare professionals must face in striving to care for humans in a world that is increasingly populated by cyborgs. However, herein lies a paradox: as person-centred care is becoming even more prominent as the gold standard for nursing care, nurses must place the human patient at the centre while navigating within an uncanny space where it is very difficult to determine "where the human ends and the machine begins" (Montiero 2016, p. 23). The use of high-fidelity simulated human patients in clinical education provides a fitting example of how the healthcare landscape is embracing the notion of the human patient as cyborg: in the same way that the human condition has become posthuman, blurring the boundaries between the dominant and central human and its material and technological others (Braidotti 2013), the simulated human patient represents an attempt to replicate an increasingly authentic facsimile of the cyborg human patient. In this way, the assemblage of simulated human patient learning is uncanny: "the familiar made somehow new and unfamiliar" (Turkle 2005, p. 290).

This conceptualisation of the simulated learning space as multiple, hybrid, and fragmented bears an uncanny resemblance to the fundamental tenets of postcolonial critical thought. The 
idea of the postcolonial subject imitating the culture of the colonisers reminds us of the uncanny mimicry of the human patient that is purposefully engendered within simulated human patients: when any attempt is made to mimic a dominant and central culture, there is always a shift away from "true" representation, creating an uncanny double of the original that is "at once resemblance and menace" (Bhabha 1984, p. 127). The purpose of this paper is to explore how elements of postcolonial critical thought can help us to understand the challenges of educating nurses to provide person-centred care within a healthcare culture that is increasingly characterised by the blurring of the borders between the human and the nonhuman. To illustrate the usefulness of postcolonial theory in this particular realm, I will draw on an empirical case study and employ these theoretical models to make clear the difficulties that nursing educators encounter as they navigate the uncanny, multiple, fragmented and complex space of teaching nursing practice with high-fidelity simulated human patient pedagogies.

\section{Simulated human patients in nursing education}

In nursing education, the single most powerful argument for engaging with simulated human patient pedagogy is that it prevents students from causing harm to real patients in their future practice "by providing a set of clinical circumstances in which it is permissible to make mistakes and learn from them" (Lewis et al., 2012, p. 88). However, others have argued that providing this distance from clinical practice and relying too much on simulation to learn clinical skills is problematic. For example, in her exploration of the importance of "validity' in simulated humans as patient models, Johnson argues that it is not how accurately the human body (or patient) is being simulated, but instead, "how well the simulated medical practices recreate those medical practices carried out by experts" (2008, p. 111). In her view, "[w]hen knowledge about the body that has been gleaned through practice is reified into a simulator, that specific phenomenon of knowing the body is simulated, not the ontologically 
independent body as such.” (2008, p. 118). In this way, the simulated human patients might represent idealised reproductions of the clinical circumstances that are being reproduced, not human patients, thereby producing learning that is based on Beaudrillard's conception of the 'hyperreal' (Fenwick and Abrandt Dahlgren 2015). This means that the distance between the real and the simulated overlaps, the boundaries between them are blurred, and the copy begins to be prioritised over the real, situating the learning on the simulation itself rather than on what is being simulated and, paradoxically, removing the link back to any clinical reality (Bligh and Bleakley 2006). Thus, while simulation aims to replace the real, the simulated human patient becomes a copy of a copy, or a simulacrum - a copy of something that does not exist (Beaudrillard 1984/1999). This translation shifts the students' perceptions of what is real and produces a reality that is unrecognisable to them when they encounter it in practice, forcing nursing educators to devise new ways of meeting the challenges of embedding simulated human patient technology in learning to care (Bligh and Bleakley 2006). In addition to this difficulty, it has been suggested that the domination of simulationbased training creates a detached island of knowledge that is exiled from the "wider world of health care and the important focus of enabling students to learn to be nurses" (Berragan 2011, p. 663), creating a paradox in that the very purpose of simulation is unintentionally being disrupted by having the complete opposite effect; that simulation actually increases the distance between learning and practice. This notion is further supported by Dunnington, who suggests that simulated human patient pedagogies might actually cause sense perception to shift, modifying the way nursing students interpret "natural human essence" (2014, p. 16). Dunnington questions how engaging with simulated humans might alter the capacity of the students to form human connections or recognise human vulnerability or value, distancing them from meaningful care. This creates a barrier to forming attachments and learning to develop and motivate the capacity for empathy, often suggested to be one of the fundamental 
elements of person-centred nursing care (Dean et al., 2016a, 2016b; Soffer 2015). Thus, as Rudge (1999) suggests, technology might actually disrupt the "essential nursing task of caring" (p. 168).

Together, these critical observations question how practice knowledge is mobilised in simulated human patient pedagogies and suggest that there is a tension between simulation technology and learning to care. This has real implications for nursing educators as they must devise increasingly divergent strategies in order to negotiate this complex, contentious and ambiguous hybrid assemblage. However, while simulated human patient technologies become increasingly ubiquitous within nursing education, the nature of the difficulty of using simulation in nursing education is rarely explored. Indeed the very nature of what is really going on in simulation - what is real and what is simulated - is poorly understood.

Particularly lacking in previous considerations of these pedagogies is the role of the educator and the difficulties and complexities that they face in their attempts to instil the ethos of person-centred care within this hybrid simulated space. Yet simulation continues to occupy a privileged position in what is considered to be the gold standard of clinical education. By drawing on key concepts in postcolonial critical thought, these taken-for-granted assumptions can be examined through a critical lens that does not prioritise technology over the human, the simulated patient over the real patient, or the medical over person-centredness. First, however, it will be useful to explore the multiple 'reals' of this uncanny simulated space in relation to the challenges that nurse educators face when navigating this domain in their attempts to make the unfamiliar familiar. To do so, I will draw on the findings of an empirical study of a group of nurse educators engaging in the teaching of immediate life support skills (cardiopulmonary resuscitation and defibrillation) to a group of third-year nursing students in a nursing school in the UK (Author 2015). This study adopted a sociomaterial approach and comprised ethnographic-inspired observations of the clinical 
skills teaching sessions followed by in-depth interviews with the nurse educators who worked closely as a team to deliver the sessions. The study was designed as a pilot to test the feasibility of taking the research forward within a doctoral research project.

\section{Multiple realities of the simulated space}

Foremost, in human patient simulation the learning space and the materialities within it are uncanny. The space is designed to look exactly like any typical hospital ward that the nursing students will already have encountered, either in their private or practice experiences. However, it is an uncanny space: it is familiar, but at the same time, unfamiliar. Here the simulated patient is prioritised, occupying a privileged position, lying on the bed. The mannequin is central, both physically, in the room, and symbolically, in becoming the focus of the care that will be simulated: patient-centred care. In a further doubling of this concept, this space becomes a completely new reality. The students are constantly reminded that this space is not real, but at the same time they must pretend that it is.

Further, the nurse educators must contend with the pedagogical 'real' of this simulated space. The students are often visibly disturbed by the uncanny 'realness' of the simulated human patient, and the nurse educators must work hard to convince them to overcome their initial aversion to the plastic cyborg so that they will begin to learn how to care for their 'patient' with empathy and engage in a performance of pretending that the simulated patient is real. In addition, the nurse educators must also negotiate the messiness of engaging with the technological real. While the students are presented with pre-programmed computergenerated scenarios that are themselves a hybrid of the software algorithms and the perceptions of practices of the programmer, the technology is unreliable and often stops working. Often the simulated human patient "crashes", or does not respond as expected, and 
the nurse educators must improvise and perform the symptoms and reactions of the simulated patient in a human doubling of the technological real.

These multiple realities that are produced within the simulated space create an assemblage of fragmented and confounding spheres that the nurse educators must navigate between, within and through in their attempts to meet the challenge of creating a space that is as closely linked to real practice as possible. Because these myriad connections mimic the conditions necessary for the postcolonial subject to emerge, postcolonialism provides an appropriate language and theoretical context in which to contribute to an understanding of the forms of hybridity and types of difficulty that emerge within this uncanny space.

\section{Postcolonial critical thought}

It is easy to fall into the trap of understanding the term 'postcolonial' as the very idea it seeks to resist. This paper considers postcolonial critical thought within a theoretical context, that is, that the postcolonial should not be considered solely in the literal sense, as the cultural space that remains after the colonisers have left. Instead, in the same way that the posthuman provides a tool with which to understand the "knowing subjects" (Braidotti 2013, p. 11) that navigate the postmodern world, postcolonialism should be considered as a tool with which to understand the world after the demise of imperialist ideology and in the midst of a paradigm shift that seeks to challenge "provincialism of the mind, sectarianism of ideologies" (Braidotti 2012, p. 11). Postcolonial critical thought, then, challenges the binary oppositions of coloniser and colonised, acknowledging that the postcolonial subject is far more complex: in the fusion of multiple cultures and identities, the demarcation between each becomes fluid, creating a space in which creativity can flourish. The great contribution of postcolonialism is that it provides a lens through which to explore our world and expand our understanding of the social connections and cultural assemblages across boundaries, both physical and 
imagined, without prioritising either the coloniser or the colonised other. In this way, the postcolonial project provides a vocabulary to challenge the oppressive epistemological and political forces of the imperialist project that still resonate around the globe today. In addition, it also provides a way of considering globalisation in the context of the ubiquitous postcolonial subject. There are few cultures, globally, that have not been influenced by imperialist forces, and equally, human cultures have always been colonised by technology. Professional nursing practice is often positioned as the colonised subaltern within the dominant medical model, with Paley famously comparing the ideology of caring to the binary opposition of slave and noble (2002). A more uncanny parallel between nursing and the postcolonial subject would be difficult to find. Despite much debate and efforts by the nursing profession to assert itself as a powerful actor in the healthcare domain, others concede that this imperialistic agency of the medical centre persists (Daly 2011). However, continuing to situate the professional nursing identity within the binary opposition of colonised and coloniser is problematic, particularly in the uncanny, fragmented and multiple landscape in which professional nurses must balance person-centred care within a space where cyborg ontology is emergent. Similarly, it is no longer appropriate to consider technology as the coloniser within nursing practice. A more significant parallel, perhaps, is the idea that nursing practice is more similar to the postcolonial subject; situated in the dynamic hybrid culture within which nursing practice is enacted, nurses are uniquely positioned as a conduit within healthcare to act as agent in allowing the subaltern patient to speak (Anderson 2000; Racine 2009, p. 184), thus placing the patient in the centre, despite suggestions that professional nursing, itself, remains silent and subaltern (Ceci 2004). This paradoxical positioning situates nurses within an uncanny (postcolonial) space: equally at home in challenging imperialist models of power, while often unable to affect the same agency for themselves within that sphere, yet drawing on the hybridity of that space in order 
to negotiate it effectively. Importantly, these are characteristics of professional nursing practice that are shared with those attributed to the postcolonial subject.

\section{The Uncanny}

We are all familiar with the idea of the uncanny, but it might best be described as a "comingling of the familiar and unfamiliar" (Royle 2003, p. 1), or the co-existence of the strange and familiar at the same time. The Freudian concept of the uncanny has long been a central theme of postcolonial critical thought, and, in considering the uncanny in relation to the pedagogies of simulated human patient, the notion of the double is a particularly appropriate starting point. First, the most obvious representation of the double is embodied within the simulated human patient itself: the mannequin resembles a human, but he is not quite human. He is inanimate, but can be provided with attributes that mimic life. He can be compared to a zombie - alive, but at the same time, not alive. The students are always visibly disturbed by the double at their first encounter, but, with the coaxing and reassuring performances of the nurse educators, they soon overcome these emotions. Bennet and Royle (1999) provide an explanation for why this zombie double is uncanny:

What makes the double uncanny? According to Freud's essay, the double is paradoxically both a promise of immortality (look, there's my double, I can be reproduced, I can live forever) and a harbinger of death (look, there I am, no longer me here, but there: I am about to die, or else I must be dead already). (Bennet and Royle 1999, p. 41)

Framing the double in these terms is particularly significant for nursing education. There are myriad doubles at work here. First there is the direct link between the purpose of this particular session - to learn how to preserve life. The simulated human patient represents the uncanny double of everything that the nursing student fears (that the patient will die while in their care) comingled with the reassurance of the immortality of the simulated human patient 
(that it is impossible for the mannequin to really die). Overlapping this double is the paradox that presents itself in engaging with an uncanny zombie double: the simulated human patient must be kept 'alive', but, essentially, he is already 'undead', rendering their efforts futile. Guided by the nurse educators to 'suspend their disbelief', the students must now embark upon a journey that straddles the border between the familiar and the unfamiliar, the alive and the undead, and the real and the simulated.

Over the course of the observations of the nurse educators as they instructed the students, a central theme of the uncanny seems to haunt the sessions. Interconnected with this everpresent element of the "disturbance of the familiar" (Bennett and Royle 1999, p. 36), the nurse educators continually draw attention to the uncanny element, reassuring the students that these disturbing feelings are normal, constantly reaffirming how the simulated human patients would not react in the same way 'in real life', but at the same time, drawing on further uncanny elements to make the simulated space more 'real'. The nurse educators do so by continually relating the 'unreal' to real lived experiences from their own practice, drawing from the previous practice learning experiences of the students, and by combining these with the experiences in the simulation space to project them forward into an imagined reality of future practice. In the simulation learning space, the students were familiar with these skills in that they may have observed them in practice placement, but at the same time they were unfamiliar to them, never yet having had the chance to practise them. By combining this disturbance of the familiar with the uncanniness of the simulated human patient, the nurse educators facilitated a hybridity of experience in order to bolster these newfound skills. In order to understand this process within a postcolonial perspective, it will be helpful to explore the parallels between the theoretical concept of diaspora and nursing practice and education.

\section{Diaspora}


While technology continues to exert its relentless influence in shaping nursing practice, nursing education has continued to adapt and respond to a landscape that is continuously shifting in movements that might be considered diasporic. In postcolonial thought, the metaphor of diaspora is a useful way of understanding the forcible movement of people who are confronted with unfamiliar, often oppressive cultures, and who must succeed in "remaking themselves and fashioning new kinds of cultural identity by, consciously or unconsciously, drawing on more than one cultural repertoire" (Hall 1995, p. 47). While navigating these fragmented and uncertain spaces, these actors can be considered to be exiles from a place which no longer exists and one to which they can never return.

As they traverse this new landscape, the exiles bring with them their precious cultural practices, but in creating a hybrid between the new culture that confronts them and the imagined traditions that they carry, they are able to deftly move within the spheres of the hybrid space, finding "new ways of being" (Hall, 1995 p. 48) in this new world. This creates an uncanny space: it is familiar, and yet, at the same time, strangely unfamiliar. For nursing education, this diasporic movement is multiple. First, the educators, while having to contend with the agency exerted by technological advancements in simulation technology, must at the same time contend with such technological developments in the practice sphere. In addition, the physical shift from the learning space from the hospital to the academy forced a cultural shift in professional nursing identity as well as within the curricula and pedagogies through which nurse educators must navigate. At the same time, the feminist movement created further slippage between each of these dispersions while further influencing the hybridity of nursing practice. Through all of these diasporic, hybrid actions, the nurse educators are accompanied by the artefacts that are embodied within technological culture such as simulated human patients. While this process has allowed the nursing profession to gain agency within the "mechanicist and organicist bio-medical model", as Monteiro observes, a 
paradox is created: while aligning with the more holistic model of person-centred care, "adopting professional practice towards technical rationality, associated with the influences of taylorization, nursing care has been transformed into an essentially technical act, arising from the medical act" $(2016$, p. 20). This notion of professional nursing practice can be seen as a parallel to the hybrid, postcolonial cultures that the imperialist project produced, positioning nursing as both a hybrid of technology and care, and as subaltern within the wider culture of person-centred healthcare that is dominated by the authoritative centre of the evidence-based medical model. Similar to the consequences of the forced diaspora of imperialism, nursing practice can never return to the time and space before this hybridity occurred. However, by the same token, this diasporic shift in ideology also has its benefits.

For example, more recently, diaspora as a postcolonial concept has come to represent circulation, movement, passage and journeying, or the activities that characterise the global, transnational and intercultural movements through, between and within locations (McLeod 2007). This theoretical concept does not relate solely to geographical movement, but instead, can provide a way of thinking about how multiple worlds are represented. The imagined journeys that the nurse educators make when gathering experiences from each of the practice spheres (their own experiences, the experiences of the students, and the imagined experiences of future practice) can be considered diasporic. As they move through these multiple realms, through a process of hybridisation, the nurse educators, in order to mobilise learning, effect a sort of créolisation of the multiple cultures of practice, technology and education.

\section{Hybridity and créolité}

Drawing from French postcolonial thought, créolité is the product of the hybrid conditions that were created by the fusion and overlapping of multiple cultures in the colonial space. As these cultures came together, the artefacts, both real and imagined, of each disparate culture 
collided, comingled and re-formed to eventually erode the dominant imperialist paradigm, replacing it with a creative freedom that more faithfully represented the richness of the culture of the postcolonial subject (Gallagher 2009). In the same way, the nursing educators, by hybridising the overlapping elements of past, present and future experiences, create the notion of créolité, incorporating both the familiar and the unfamiliar to provide a more authentic link between the real and the imagined practices that are enacted in simulation learning. While the postcolonial concept of créolité served as a tool to resist the oppressive agency of the coloniser, this notion of hybridity as resistance is useful for opening up new ways of thinking about how nurse educators might meet the challenge of embedding personcentred care within simulated human patient pedagogies.

In seeking to understand technology as a potentially oppressive and uncreative force in health care education, postcolonial critical thought, then, provides a way of thinking about personcentred care that goes beyond the notion of the cyborg patient or the hybrid of the human and technology. Instead, the complexities of this particular network are imbued with multiple hybridities situated within and across manifold overlapping domains that can also be considered postcolonial. Other nursing philosophers have successfully employed postcolonial feminist thought to explore important theoretical considerations such as the idea of challenging issues of health inequalities in nursing scholarship (Racine 2009) and in considering the historical agency of the nursing profession to understand and develop nursing knowledge (Sochan 2011). However, particular to simulated human patient pedagogies in nursing education is the multiple layering of the hybrid of human and technology and the added practice spheres that must act as a scaffold between nursing education and nursing practice. For this reason, the postcolonial concepts outlined in this paper are perhaps better suited in forming a more nuanced understanding of the difficulties associated with using simulation to promote the ethos of person-centred care in health education. 


\section{Conclusion}

In postcolonial thought, the space of the colonised, where créolité is enacted, is uncanny: the new culture is a simulated double of the imperial centre; but, because of its hybridity, it seems familiar, but at the same time, strangely unfamiliar. Considering human simulation in nursing education within an understanding of postcolonialist thought, I would argue that the hybridity goes beyond that of mere fusion of the human and technology: instead, the complexities of this particular network are characterised by assemblages of multiple hybridities situated within and across manifold overlapping domains that can also be considered postcolonial. In fact, much of the language used in critical reflection of this trend towards a hybrid ontology has its roots within the ideas developed by postcolonial critical theorists.

While this study was specifically related to nursing students, these tensions between the human and technology might be an issue in other simulation learning spaces. For professional educators, there is a need to encourage dialogue about the recognition of the uncanny effects that create multiple paradoxes as well as unique forms of learning within simulation education. The uncanny relationship between the simulacra that is the simulated human patient and the posthuman condition is present but rarely discussed. These tensions between technology, cyborg, and person-centred care will continue to haunt clinical education and practice until they are more closely examined and a better understanding of the influence of the simulated human is achieved. Because of the parallels that can be drawn between the postcolonial subject and professional nursing practice and education, it can be suggested that the elements of postcolonial critical theory discussed here can offer an appropriate way of opening up new possibilities in exploring and understanding the pedagogy of human patient simulation in nursing education and beyond. 


\section{References}

Anderson, J.M. (2000) Gender, 'race', poverty, health and discourses of health reform in the context of globalization: a postcolonial feminist perspective in policy research. Nursing Inquiry 7(4), 220-229.

Bennett, A. and Royle, N. (1999) Introduction to Literature, Criticism and Theory, 2nd edn. Harlow: Pearson Education Limited.

Berragan, E. (2011) Simulation: An effective pedagogical approach for nursing? Nurse Education Today 31(7), 660-663.

Beaudrillard, J. (1984/1999) Simulacra and Simulation (S.F. Glaser, trans). The University of Michigan Press; Ann Arbor.

Bhabha, H.K. (1984) Of Mimicry and Man: The Ambivalence of Colonial Discourse.

October 28, Discipleship: A special Issue on Psychoanalysis (Spring), 125-133.

Bligh, J. \& Bleakley, A. (2006) Distributing menus to hungry learners: Can learning by simulation become simulation of learning? Medical Teacher 28(7), 606-613.

Braidotti R. (2013) The Posthuman. Cambridge: Polity Press.

Ceci, C. (2004) Nursing, knowledge and power: A case analysis. Social Science \& Medicine 59(9), 1879-1889.

Daly, L.K. (2012) Slaves immersed in a liberal ideology. Nursing Philosophy 13(1), 69-77.

Dean, S., Williams, C., \& Balnaves, M. (2016a) Living dolls and nurses without empathy. Journal of Advanced Nursing 8 January 2016, Early View. 
Dean, S., Williams, C. \& Balnaves, M. (2016b) Practising on plastic people: Can I really care? Contemporary Nurse 51(2-3): 257-271.

Dunnington, R.M. (2014) The nature of reality represented in high fidelity human patient simulation: philosophical perspectives and implications for nursing education. Nursing Philosophy 15(1): 14-22.

Fenwick, T. \& Abrandt Dahlgren, M. (2014) Towards sociomaterial approaches in simulation education: lessons from complexity theory. Medical Education 49(4), 359-367.

Forss, A. (2015) Nursing’s Nightingale Needed a Lamp! In: Technoscience and Postphenomenology: The Manhattan Papers (eds J.K.B.O. Friis and R.P. Crease) pp.161168. Lexington Books, Lanham, MD.

Gallagher, M. (2009) Aimé Césaire and Francophone Postcolonial Thought. In: Postcolonial Thought in the French-Speaking World (eds C. Forsdick and D. Murphy) pp. 31-41. Liverpool: Liverpool University Press.

Hall, S. (1995) New Cultures for Old. In: A Place in the World: Places, Culture and Globalization (eds D. Massey and P. Jess), pp. 175-213. Oxford: Oxford University Press. Johnson, E. (2008) Simulating medical patients and practices: Bodies and the construction of valid medical simulators. Body \& Society, 14(3):105-128.

Lewis, R., Strachan, A. \& McKenzie Smith, M. (2012) Is high fidelity simulation the most effective method for the development of non-technical skills in nursing? A review of the current evidence. The Open Nursing Journal 6, 82-89.

McLeod, J., ed. (2007) The Routledge Companion to Postcolonial Studies. Oxford: Routledge. 
Monteiro, A.P.T.D.A. (2016) Cyborgs, biotechnologies, and informatics in health care-new paradigms in nursing sciences. Nursing Philosophy 17(1), 9-27.

Paley, J. (2002) Caring as a slave morality: Nietzschean themes in nursing ethics. Journal of Advanced Nursing 40(1), 25-35.

Racine, L. (2009) Applying Antonio Gramsci's philosophy to postcolonial feminist social and political activism in nursing. Nursing Philosophy 10(3), 180-190.

Royle, N. (2003) The uncanny. Manchester: Manchester University Press.

Rudge, T. (1999) Situating wound management: technoscience, dressings and 'other' skins. Nursing Enquiry 6, 167-177.

Sochan, A.M. (2011) Stance and strategy: post-structural perspective and post-colonial engagement to develop nursing knowledge. Nursing Philosophy 12(3), 177-190.

Soffer, A.K.B. (2015) Replacing and representing patients: Professional feelings and plastic body replicas in nursing education. Emotion, Space and Society 16, 11-18.

Turkle, S. (2005) The Second Self: Computers and the Human Spirit, Twentieth Anniversary Edition. London: The MIT Press. 